\title{
A PINTURA DE ESTEVÃO SILVA E SUA RELAÇÃO COM A BRASILIDADE
}

\author{
Cristina Pierre de França \\ Colégio Pedro II \\ UFRJ- Programa de Pós-Graduação em Artes Visuais \\ UNIGRANRIO
}

O pintor Estevão Roberto da Silva, foi um artista ligado à Academia Imperial de Belas Artes, como de resto a maioria dos pintores do período. Filho de pais africanos, consta que nasceu em Niterói em 26 de dezembro de $1845,{ }^{1}$ tendo falecido, dormindo, em 9 de novembro 1891, de causas desconhecidas ou pelo menos nebulosas.Um artista de natureza solitária e intimista razão que talvez, explique sua predileção pela pintura de naturezas-mortas. Um gênero que na Academia era ministrado na cadeira de "Pintura de paisagem, flores e animais".

A atuação de Estevão Silva no cenário da arte nacional só recentemente está sendo reavaliada e estudada. ${ }^{2}$ Geralmente era atribuído ao pintor um papel menor, num "plano secundário"3 dentro do cenário de artes plásticas no país; conseqüência direta do momento vivido pelo Brasil durante os Oitocentos.

Desde o início do século XIX, o governo do Brasil implementa uma série de ações, cujo propósito era de construir uma imagem nacional e uma idéia de civilização.

Esta imagética de exaltação e de idealização da pátria, segundo esse projeto, se configuraria a partir de temas históricos, dos

\footnotetext{
1 Não existe ainda um estudo aprofundado e preciso a respeito do pintor, não havendo muitos registros de sua vida privada. Essas primeiras informações que destacamos são retiradas de José Roberto Teixeira Leite. Pintores negros dos oitocentos. São Paulo, MWM. Motores Diesel Ltda. Indústrias de Freios Knoor, 1988. p. 116.

2 Além de reavaliações em livros e Catálogos que tratam da questão do negro na Arte Brasileira, existem trabalhos que se situam na avaliação de seu trabalho e na valorização de sua obra a luz da produção de arte nacional do período. Destacamos a Dissertação de Mestrado recentemente apresentada por Alexandre Neiva Pessôa, no programa de e Pós-Graduação de Artes Visuais da UFRJ, com o título Estevão Silva e as pinturas de naturezas-mortas no Brasil do século XIX e minha própria dissertação. Estevão Silva e Hélio Oiticica. Brasilidade, A sensação Revisitada, defendida nesse mesmo programa.

3 Acquarone, Francisco e Vieira, A. de Queiroz. Primores da Pintura no Brasil - $2^{\circ}$ volume, Rio de Janeiro, s.e, 1942. sem paginação.
} 
quais eram representados fatos que consolidariam e unificariam a idéia de país, e simultaneamente a de nação e civilização.

Nesse sentido, tanto Estevão Silva, como os artistas que se dedicavam ao gênero de pintura histórica eram classificados como artistas de segunda categoria. Apesar do reconhecimento de seu valor por como Francisco Acquarone e A. de Queiroz Vieira.

Apresentamos um olhar contemporâneo de valorização da produção de Estevão, entendendo que algumas das propostas estéticas executadas em suas telas permitem ver algumas singularidades e mudanças que permeavam a produção daquele momento da arte brasileira. Acreditamos que a pintura de naturezamorta lhe oferecia modos de escapar à ortodoxia da produção da época, de conduzir seu trabalho com mais liberdade do que se dedicasse aos retratos ou à pintura histórica - os gêneros mais municiados pela Academia.

Estevão Silva ingressou na Academia Imperial em $1863^{4}$ e a ela esteve ligado por grande parte de sua vida. Foi aluno de Victor Meirelles, Jules Lê Chevrel, e Agostinho José da Motta, este último, de quem provavelmente herdou a apreciação pelo gênero de natureza-morta.

Agostinho José da Motta (1824- 1878) foi o professor que mais influenciou Estevão Silva. Foi dele que Estevão Silva absorveu o interesse no que diz respeito à predileção por pintar frutas. Nasceu no Rio de Janeiro e trabalhou como mestre da cadeira de paisagem na Academia de Belas Artes, da qual também foi aluno. Seu ingresso nesta instituição data de 1837. Agostinho trabalhou como professor tanto na Academia Imperial de Belas Artes quanto no Liceu de Artes e Ofícios. Participou de diversas exposições gerais entre os anos de 1850 e 1875.

Outro mestre que exerceu poderosa influência sobre Estevão Silva foi Georg Grimm, que após a saída da Academia de Belas Artes fundou um núcleo de pintores paisagistas, que tinham como meta a pintura de paisagem ao ar livre.

\footnotetext{
${ }^{4}$ Optamos por essa data apesar de estar relacionado no Boletim de Belas Artes o ano de 1864, porque se encontrou no Museu Dom João VI registro de um incidente com um guarda da Escola de Belas Artes, no qual estavam envolvidos alguns alunos entre os quais encontramos o nome e o registro do relato do incidente feito também por Estevão Silva.
} 
Apesar de ter incursionado por algumas aventuras junto ao grupo, de estar dentro do círculo de relações, Estevão nunca fez de fato parte do Grupo Grimm, como ficou conhecido esse núcleo de artistas.

As naturezas-mortas de Estevão Silva, pintadas com verdade e sinceridade, forneciam ao espectador uma gama de sensações que superavam a instância visual. Suas frutas pintadas, levavam ao fruidor à vontade de fato de saboreá-las. Esta confirmação pode ser encontrada tanto no anedotário mais ingênuo com respeito a sua obra, como nessa passagem narrada por Manoel Carneiro, em sua crítica à exposição de Estevão realizada no Liceu de Artes e Ofícios, oportunidade em que nos conta essa passagem de quando percorria a exposição com o artista:

\footnotetext{
"Um dos alunos do Lyceu, de 8/9 anos visitava a exposição, devorando com o olhar aquelas frutas apetitosas, (...) desafiarem-lhe a gulodice e longe de alcançar a mão (...) Meteu a mão no bolso e, com um níquel em punho dirigiu-se ao pintor que conversava comigo a um canto da sala:

-Quanto custam aquelas mangas? Quero levar uma a mamã, que é douda por elas (...)Pusemo-nos a rir." 5
}

Esse sentimento não era resultado de uma visão infantil; As sensações que experimentamos excediam os aspectos visuais de suas telas.

Desse modo, torna-se importante assinalar o procedimento pictórico do artista, em que simultaneamente repete a atitude realista ao pintar suas frutas diretamente do real numa composição em que os objetos pintados, já em sua origem apresentam uma deliberação do pintor.

Essa realidade que Estevão Silva apresenta é tão próxima, que diversas observações alusivas a sua obra comentam a respeito de sensações que ultrapassam a questão visual, tocam de perto sensações como o olfato e o paladar.

“Às vezes despertam desejos os seus quadros, desejos inocentes de trincar a talhada de uma melancia rubra e partida, uma romã aberta como uma boca de menina, numa provocação acesa de beijos. São quadros da sala de jantar. E que diabólico aperitivo!

Nas paisagens o visitante pára diante de cada tela e tem para ocupá-lo apenas a execução do trabalho, o pensamento e o sentimento do pintor. Diante de um quadro de frutas não tem outro desejo que o de aplaudir a execução quando elas são pintadas pelo Sr. Estevão Silva. O desejo de comê-las vem um pouco mais tarde, o que comprova a perfeição dos trabalhos." 6

${ }^{5}$ Carneiro, Manoel.Diário Ilustrado. Bellas-Artes. Rio de Janeiro. 21-07-1887. p. 1.

${ }^{6}$ M.C. Diário Ilustrado No 97 Bellas-Artes, Rio de Janeiro, 21-7-1887. p. 1. 
Pode-se observar que estavam lado a lado na crítica ao trabalho de Estevão Silva as seguintes questões: a do realismo de suas produções que aludem às sensações provocadas pelo próprio objeto representado. Para Manoel Carneiro, em um de seus artigos, os seus trabalhos apresentavam "a pureza das tintas e a verdade das cores". 7 No caso das frutas remetem ao seu odor e sabor. A outra questão é a recorrência do pintor de trabalhar com as frutas nacionais:

"Mangas, as saborosas mangas, que, na opinião de Alencar, tanto influenciam para adocicar a pronunciação brasileira: São de amarelo quente, banhado de rubro. Colhidas ao tempo. Bem sazonadas. (...)

Esses três pratos foram pintados por Estevão Silva, um artista que tem demonstrado verdadeira paixão por esse gênero. Pintá-los assim é difícil, pintá-los melhor é impossível. Nas frutas nada mais se pode desejar, mas onde o artista podia emendar-se é nas sombras. As sombras projetadas carregam muito o conjunto "

Em se tratando de Estevão Silva, compreendemos que a escolha de frutas foi mais que uma opção de pintura, foi a sua forma de expressar a sua verdade na pintura, uma vez que o artista tinha uma atitude e um procedimento de execução de suas obras similar àqueles dos realistas.

Além disso, suas naturezas mortas mostram a peculiaridade de um lugar específico, ele trabalha com frutas reconhecidamente brasileiras, fato esse que não deixa de ser assinalado pelos críticos de seu período.

A respeito de sua exposição de 1887, Manoel Carneiro assinala que esta é o resultado de três anos de trabalho assíduo. Nessas telas, Estevão Silva sempre está se relacionando e privilegiando a pintura de frutas. Esse tipo de representação insere sua obra numa tradição de natureza-morta que remete a questões que se configuram sob o domínio do sensório.

Segundo Meyer Shapiro, a genealogia do gênero e do motivo privilegiado por Estevão Silva se inscreve numa prática que tradicionalmente alude à sensação. A própria etimologia do termo remete ao sensório, uma vez que a palavra fruta - "fructus" deriva do verbo latino fruor, o qual tem seu sentido primitivo relacionado à idéia de "satisfação, gozo, deliciamento" dos sentidos. Assim, as frutas, por seu "volume

\footnotetext{
${ }^{7}$ Carneiro, Manoel. in Diário Ilustrado. Rio de Janeiro, 13/5/1887. p. 2.

${ }^{8}$ Palheta, Alfredo (pseudônimo de Gonzaga Duque). A Semana. Bellas-Artes. No126 Rio de Janeiro, 2805-1887.
} 
atraente, lindas cores, textura e forma", ${ }^{9}$ apresentando uma condição que as relacionam ao prazer e superam a simples contemplação visual, agregam também sensações de paladar e olfato. Dessa maneira devemos compreender que a opção de Estevão Silva de privilegiar as frutas deve-se a essa instância prazerosa à qual a fruta remete.

Estevão Silva foi além dos aspectos sensoriais ao pintar apenas frutas que pertenciam efetivamente ao dia-a-dia brasileiro. Não é por outra razão que ele apresenta mangas, abacaxis, bananas, goiabas, frutas-deconde, tangerinas, jabuticabas, romãs, entre outras frutas, como apregoa Elói, o herói, isto é, Arthur de Azevedo, em uma de suas críticas à exposição do artista:

\begin{abstract}
"Visitem a exposição de quadros de Estevão Silva.
Este pintor tem uma especialidade; as frutas, pinta-as com uma perfeição admirável; não me parece que nesse gênero encontre no Brasil competidor que o exceda, nem mesmo o iguale. Há nos seus quadros ananases, mangas, ameixas, cambucás, laranjas, carambolas, melancias etc., que fazem crescer água na boca, tal é a verdade e a consciência com que estão reproduzidos. O Estevão tem delicadeza do toque e certeza do colorido e contorno, é um hábil pintor de natureza-morta, que não deve fugir de sua especialidade." 10
\end{abstract}

Essas frutas muitas vezes são típicas de clima tropical como o nosso e fazem parte de uma identidade diferenciada e do cotidiano do país. Com certeza não figuram na tradição pictórica da naturezamorta de frutas, que se concentra na representação de frutas de países temperados como as maçãs, as uvas, as pêras, morangos e framboesas, mas em frutas que estão relacionadas ao cotidiano do Brasil do século XIX.

Apesar de ser considerado um pintor acadêmico, ${ }^{11}$ Estevão Silva transita entre práticas diversas daquelas que a Academia defendia, e certamente apresenta a tensão existente na pintura durante o século XIX na Europa e também no Brasil. ${ }^{12}$ A tensão estava localizada entre uma

\footnotetext{
9 Shapiro, Meyer. "As maçãs de Cézanne" in A Arte Moderna - séculos XIX e XX. S. Paulo. EDUSP, 1996. p. 39.

${ }^{10}$ Elói, o herói. Novidades/ Folha da Tarde, De Palanque. Rio de Janeiro.16-7-1887. p. 1.

${ }^{11}$ Sempre que se comenta a produção de Estevão Silva ela está inserida entre a produção dos artistas ligados à Academia, não são percebidas as nuances de sua obra que já relativizam o pensamento idealista acadêmico no que diz respeito ao realismo e ao mundo fenomênico expressos em sua obra. Ver Gonzaga Duque. Adolfo Morales de los Rios e Quirino Campofiorito, obras já citadas neste trabalho.

${ }^{12}$ Podemos exemplificar esse fato no Brasil a partir da existência do Grupo Grimm.
} 
realização que se conjugava com os valores clássicos e as novas especulações e experimentações que se apresentavam na arte desde o Romantismo e que continuaram presentes e se radicalizaram no Realismo e no Impressionismo. Apesar de não haver uma produção textual ou depoimentos do próprio pintor, suas obras mostram esse conflito entre a fatura acadêmica e as novas tendências, entre o belo ideal e o real.

Podemos divisar o seguimento desses preceitos na sua tela de Natureza-Morta com melão, bananas e mangas. Nessa tela, estão expostas diversas frutas tropicais como cajus, abacaxi, melão, mangas - as quais estão colocadas diretamente sobre um piso indefinido. Numa fruteira em plano mais afastado, vemos frutas como a maçã e a pêra, além de um mamão e pequenas frutas. A composição apresenta uma forma que se enquadra entre circular espiralada e o triangulo, ambos dominados pela figura do melão, em que todos os elementos estão limitados por linha precisa - característica da forma acadêmica.

Entretanto, apesar disso a luminosidade apresentada nessa tela não era comum na produção acadêmica, principalmente pelo uso de cores luminosas, particularmente do amarelo, dando ao quadro uma intensidade de iluminação que não aponta para o modo clássico de visualidade. Essa característica de uso preferencial de determinados matizes intensos foi assinalada por alguns comentadores, como é o caso de Gonzaga-Duque que destaca a "prodigalidade de vermelhos, de amarelos e de verdes"13 na obra de Estevão . O texto que se segue, de uma exposição realizada cerca de 60 anos após a sua morte destaca a qualidade em suas pinturas:

"Especializou-se em natureza-morta. De fatura meticulosa, segura, colorido intenso na gama dos amarelos, sua obra mostra conhecimento profundo do assunto e qualidades bastante desenvolvidas. As frutas em geral eram mais bem entonadas que as flores."14

Por outro lado, Estevão Silva pode subverter esses parâmetros ao realizar trabalhos em que sua fatura assume deliberadamente uma pincelada mais solta, como se a tinta quisesse sair da tela e ganhar sua autonomia.

\footnotetext{
13 Transcrição de Gonzaga-Duque in Contemporâneos citado in Mostra do Redescobrimento: negro de corpo e alma. Org. Nélson Aguilar. Fundação Bienal de São Paulo. São Paulo: Associação Brasil 500 Anos ;artes Visauis, 2000. p. 324

${ }^{14}$ Leal, Regina Monteiro. Catálogo "Panorama Um Século de Pintura (1850-1950)", Rio de Janeiro, MNBA. p. 36.
} 
Tal procedimento pode ser observado em obras em que a linha e a fatura não são tão precisas,suas pinceladas se diluem, tornam-se imprecisas, num tratamento que, com certeza, não é preconizado pela Academia. Não obstante essa característica, no primeiro e no último plano Estevão nos apresenta uma manga e bananas maduras, estas frutas trazem em sua superfície as marcas de uma realidade que revela o seu caráter perecível e absolutamente frágil.

Suas frutas não são apresentadas isoladamente ao espectador, muitas vezes parecem ter sido arrancadas das árvores, retiradas momentos antes do pé. Junto a elas estão os ramos das árvores que as sustentavam e que as ligavam à árvore-mãe e que as mantinham ainda vivas, como se fossem fragmentos da própria natureza.

Elas apresentam o mesmo recorte das naturezas mortas de Courbet - no sentido que tal como o pintor francês "mantêm a haste e as folhas, que dão ao conjunto o aspecto de um segmento vivo da natureza colhido por um homem de apetite gigantescamente sensual"15 que estendem sua significação para além da mera representação das frutas, são recortes da paisagem.

A pintura de Estevão Silva proporciona uma meta-linguagem da atividade pictórica à medida que se delineia um recorte do recorte.

Suas naturezas-mortas são fragmentos da paisagem, que por si só podem ser compreendidas como um recorte da natureza. Suas telas asseveram que o pintor é um construtor dessa natureza e que constrói de forma permanente o que é mutável e instável.

Esse paralelo com a natureza pode ser assinalado em obras em que o pintor privilegia uma forma de arte tirada da tradição pictórica das naturezas-mortas, principalmente as de origem latina, ao colocar suas frutas em ramos verticais, assinalando um paralelo com sua posição real no próprio mundo contingente.

As telas reproduzem respectivamente: limão, jabuticabas e tangerinas. Em todas as telas, as frutas estão representadas junto a seus galhos originais na posição vertical.

Essa posição reforça o sentido de verdade com o qual Estevão retrata seus quadros. A verticalidade das frutas alude à verticalidade do reino vegetal no qual elas estão inseridas, numa posição similar à da árvore.

\footnotetext{
${ }^{15}$ Meyer Shapiro . As maçãs de Cézanne in Arte Moderna; Séculos XX e XX. São Paulo. EDUSP, 1996. p. 68
} 
As obras de Estevão apresentam uma peculiaridade, suas naturezas-mortas não compõem um ambiente fechado e enquadrado de uma sala de jantar ou um canto da sala perto da janela. Antes, estão marcadas pela imprecisão de local determinado em seu sentido interior. Dessa maneira, não podem ser percebidas com o intuito de decorar apenas, elas dominam a composição e simultaneamente são claramente expostas ao olhar e à avaliação do espectador.

Suas frutas não se dirigem apenas ao olhar, remetem ao paladar. Abertas, são um convite a que o espectador rememore seu sabor, construindo na memória através de composições, reveladas pela cor e a umidade da fruta fendida

Sua representação se encaminha de forma similar ao próprio ato da alimentação que se constitui a partir do cheiro, depois da visão e por fim do próprio paladar do alimento, como nos revela Manoel Carneiro em sua descrição das sensações provocadas pelos quadros de Estevão Silva:

“... na exposição, sente-se o prazer de quem olha para uma mesa aberta de flores frescas e belos frutos maduros. Às vezes despertam desejos os seus quadros, desejos inocentes de trincar a talhada de uma melancia rubra e partida, uma romã aberta como uma boca de menina, numa provocação acesa de beijos."16

Desse modo, os figos, maracujás, melancias, mangas, abacates e tangerinas estão prontos para aplacar nosso apetite.

Essas telas são um convite à fruição sensorial que não se compraz apenas nos aspectos visuais, associam-se aos outros sentidos que se estabelecem a partir da realidade com que são pintadas. Despertam diante de suas telas rememorações, avivamentos das sensações; similar às produzidas diante das frutas reais. Esta afirmativa pode ser observada diante da crítica que se segue, assinada por Alfredo Palheta, pseudônimo de Gonzaga Duque:

“...mangas, as saborosas mangas, que, na opinião de Alencar, tanto influenciam para adocicar a pronunciação brasileira: São de amarelo quente, banhado de rubro. Colhidas ao tempo . Bem sazonadas. Figos, belos figos, ouvides, apetitosos, de uma cor escura, descendo para a cor do vinho tinto Açor. Um cacho de cocos de tucuns, parecidos na forma e no colorido com uvas pretas do Douro, magníficos pelo sabor. Róseos jambos, aveludados pêssegos, corados de carmim, macios araçás, pitangas de gomos

16 Carneiro, Manoel. Diário Ilustrado. Bellas-Artes, No 97, 21-7-1887. p. 1. 
escarlates, e um mamão aberto ao meio em talhado, fruto insosso ao paladar delicado, porém querido dos pequenos pássaros cantores ..."17

Desse modo, são recorrentes em sua obra a apresentação de frutas abertas, fendidas ou machucadas, de modo a assinalar a sua função altamente palatável, de exacerbar a idéia de seu sabor .

Além desse aspecto, a obra de Estevão Silva apresenta uma outra característica. Algumas vezes suas frutas apresentam-se diretamente sobre a terra. Acreditamos que esse caráter, alinhado à intenção do artista de apresentar frutas referentes ao Brasil, reflita a intenção de representar o próprio país. A ligação entre a fruta e a terra é universal, mas quando o pintor utiliza-se de frutas brasileiras junto à terra, algumas vezes de maneira explícita, outras de maneira implícita pela imprecisão do local e pela aproximação via cor desses dados sensoriais, remete à idéia de uma terra específica e identificável ou pelo menos relacionada a essas mesmas frutas consumidas no país.

Além disso, Estevão Silva, reforça essa idéia ao assinalar em suas telas o local em que elas foram pintadas, lê-se claramente o nome do país, como um adendo de reconhecimento ou de reforço de uma idéia de país que ele deseja enfatizar.

Com um olhar contemporâneo pode-se afirmar que naqueles anos do final do século XIX estavam-se realizando experiências no domínio das sensações que só se potencializariam no século XX. Em outras palavras, pode-se dizer que algumas das experimentações levadas a cabo naquele século se desdobraram em efetividade apenas no século que se seguiu.

$\mathrm{O}$ século $\mathrm{XX}$ é o momento em que se radicalizariam essas experiências propostas inicialmente nos oitocentos, não só pelas questões técnicas que elas agregam, mas também pelas possibilidades que foram instigadas, principalmente em relação ao pensamento artístico. Se durante o século XIX a única fala de nossos artistas se circunscreve a sua produção, no século seguinte entraríamos de fato na era da reflexão e do pensamento deles próprios a respeito de sua produção.

\footnotetext{
${ }^{17}$ Palheta, Alfredo. A Semana. Belas-Artes. Rio de Janeiro, nº 126. 28-05-1887. p. 4.
} 